URBAN FORAGING: INDIVIDUAL VARIATION IN INNER-CITY GRAFFITI WRITERS' TARGET PREFERENCES AND SPECIALIZATION

Elias Neirynck, ${ }^{1,2}$ Christophe Vandeviver, ${ }^{1,2}$ Luc Lens $^{3}$, \& Tom Vander Beken ${ }^{1}$

${ }^{1}$ Department of Criminology, Criminal Law and Social Law, Ghent University, Ghent, Belgium.

${ }^{2}$ Research Foundation-Flanders (FWO), Brussels, Belgium.

${ }^{3}$ Department of Biology, Ghent University, Ghent, Belgium.

Direct correspondence to: Christophe Vandeviver, Department of Criminology, Criminal Law and Social Law, Ghent University, Universiteitstraat 4, 9000 Ghent, Belgium.

Email: Christophe.Vandeviver@UGent.be

Declaration of interest: None. 


\title{
URBAN FORAGING: INDIVIDUAL VARIATION IN INNER-CITY GRAFFITI WRITERS' TARGET PREFERENCES AND
} SPECIALIZATION

\begin{abstract}
Objectives: Drawing upon optimal foraging theory, we examine graffiti writers' individual target preferences to establish the diversity in their target choices (henceforth called "target specialization"). Ecological research implies that the total population of writers can consist of target specialists, generalists, or both. Target preferences are either similar or dissimilar among individuals.
\end{abstract}

Methods: One year of graffiti removal data relating to 1,904 incidents committed by 263 individuals were extracted for a medium-sized city in Belgium. Individual target specialization and preferences were analyzed using ecological network methods.

Results: The total diversity in target choices at the aggregate level is primarily the result of substantial between-individual variation. The results indicate that the total population of graffiti writers largely consists of target specialists, and can be divided into subgroups that share similar target preferences. Aggregate patterns of target selection do not accurately reflect individual variation in target choice specialization, at least for graffiti writing.

Conclusions: We recommend future research to account for individual differences in target specialization. The patterns observed here are similar to those observed in animal ecology studies supporting the idea that crime patterns might correspond to common behavioral ecological patterns.

Keywords: Environmental criminology, Behavioral ecology, Optimal foraging, Network analysis, Graffiti

\section{INTRODUCTION}

The process of selecting and exploiting targets is a necessary element for any criminal event to occur (Cohen and Felson 1979). Although criminal target preferences have been studied extensively, research that explicitly takes differences in target selection between offenders into account is limited. Most models are based on the underlying assumption that target preferences are similar for all offenders, an assumption that is increasingly being challenged (Townsley et al. 2016; Townsley and Sidebottom 2010; Van Daele 2010). It remains an open question in how far it is warranted to assume that betweenindividual variation is negligible across different offense types.

The question how aggregate patterns of target choices result from between-individual differences has not been explicitly addressed in criminology, yet the answer has implications for the way we theorize and model criminal decision-making. If such variation in target choices is large, any given rationale behind target selection strategies might be accurate at the population level, but is likely inadequate to explain individual strategies, and subsequently, unable to translate into efficient crime prevention initiatives. Given this, it is essential to understand under which circumstances between-individual target choice variation is likely to arise, and thus, when the need for individual-based accounts is high. If what is observed at the population level is an emergent property of individual target choices, measuring exactly how between-individual variation gives rise to particular aggregate patterns is the first step in trying to explain why target choices are structured the way that they are.

In addition, research has largely focused on instrumental offenses, such as residential burglary (e.g., Bernasco and Nieuwbeerta 2005; Langton and Steenbeek 2017; Townsley et al. 2015; Vandeviver et al. 2015a), car theft (e.g., Brantingham 2013; Clarke and Harris 1992; Light et al. 1993), and armed robbery (e.g., Bernasco and Block 2009; Jacobs 2010; Jacobs 2000; Wright and Decker 1997). However, target selection processes of expressive offenses such as graffiti writing have received considerably less 
scholarly attention. Empirical research on graffiti has mostly been limited to ethnographic accounts (e.g., Ferrell 1993; Halsey and Young 2006) or aggregate spatial analyses (e.g., Haworth et al. 2013; Megler et al. 2014), which limits our understanding of graffiti writers' decision-making. Ethnographic studies rarely allow for inferences at the population-level, while aggregate analyses make it impossible to disentangle differences between individual graffiti writers.

Like other offenders (Cornish and Clarke 1986), graffiti writers are believed to be rational decisionmakers who prefer high-value and low-risk targets over targets that offer little gains and require substantial effort to overcome (Ferrell and Weide 2010). However, graffiti writers do not capitalize on all criminal opportunities, but only some while ignoring others. Instead, they might have an operational range of preferred targets that is sufficiently diverse for their needs (Felson 2006). This is similar to how animals select prey, who tend to ignore particular prey items when more profitable prey items are abundant (Pulliam 1974). There is a rich body of animal ecology research dedicated to why some animal species have more specialized diets compared to others (Krebs et al. 1996; Stephens and Krebs 1986). One noteworthy branch of research uses optimality modeling to investigate the foraging decisions animals face, aptly branded Optimal Foraging Theory (OFT), which resulted in a number of highly detailed formal models and a priori hypotheses with regard to what animals forage (Charnov 1976b; Sih and Christensen 2001), where animals forage (Nonacs 2019), when animals forage and for how long (Charnov 1976a; Marshall et al. 2013), how animals forage in group (Giraldea and Pyke 2019; Waite and Field 2007), and how animals move while foraging (Pyke 2019).

These studies have in turn served as the inspiration for criminological research, for example when investigating car thieves' target choices (Brantingham 2013). Analogous with the literature on animal foraging behavior, it is one thing to ask what targets offenders prefer and another how selective or versatile offenders are in their target choices (Bernasco 2009). In what follows, we will refer to graffiti writers' breadth of preferred targets as target specialization to improve the readability of the paper. Though target preference and target specialization are related (but distinct), the latter aspect of criminal decision-making has not received direct attention to date. Yet, better insight into the degree and structure of criminal target specialization adds to a broader understanding of the way crimes are carried out, which aids the development of effective crime prevention initiatives.

In studying target specialization patterns in the decision-making of graffiti writers, we advance prior literature in two ways. First, we simultaneously evaluate individual differences in target preferences and specialization. To do so, we draw on Optimal Foraging Theory in which questions of prey specialization are explicitly addressed (e.g., Charnov 1976b). Second, we add to the limited research on urban graffiti writers' target selection by combining analyses at the aggregate and individual level.

This article is structured as follows. First, we frame target specialization within the criminal decisionmaking literature and discuss target specialization within Optimal Foraging Theory. Second, we discuss graffiti writers' target specialization. Research questions are formulated and evaluated using graffiti removal data. Next, we describe the data and methods. This is followed by a presentation of the research results. Finally, we conclude this paper with a discussion of the findings and the implications for future research, graffiti prevention initiatives and criminological theory in general.

\section{TARGET PREFERENCES VERSUS TARGET SPECIALIZATION}

A large body of research is dedicated to the question what targets offenders prefer for a wide array of crime types (e.g., Bernasco and Nieuwbeerta 2005; Clarke and Harris 1992; Jacobs 2010; Jacobs 2000; Light et al. 1993; Nee and Taylor 1988; Townsley et al. 2015; Vandeviver et al. 2015a; Wright and Decker 1996; 1997). However, one could also ask whether offenders favor a broad range of possible 
targets, or conversely, specialize on a narrow subset instead (Bernasco 2009). The distinction between both aspects of criminal decision-making has implications for both research and crime prevention initiatives. A broad range would indicate that offenders (or a subgroup among them) are not very selective in terms of their target choices. This implies that a large variety of target types is capable of meeting those offenders' needs, suggesting that offenders are satisficers rather than optimizers when searching for targets (Simon 1955). Another way to look at this is to say that these offenders' target selection is opportunistic instead of planned. Subsequently, situational crime prevention initiatives (e.g., Clarke 1992) may be more successful in deterring specialized offenders than target generalists, since those offenders have fewer alternatives to fall back on.

There has been little direct scholarly attention within criminology to the topic of target specialization, although it has been implied that offender populations may consist of both target specialists and generalists. For example, some armed robbers prey almost exclusively on other criminals, such as drug dealers (e.g., Jacobs 2000), while others diversify by including non-criminal victims as well (Wright and Decker 1997). Similarly, in an experimental study by Nee et al. (2015), experienced burglars seem to take a more narrow range of items compared to a control group of students, indicating that criminal expertise is likely associated with target specialization. The crime displacement literature mentions the possibility that offenders adapt to increased crime prevention initiatives by changing their preferred targets (e.g., Reppetto 1974), but does not account for the possibility of target specialization.

Within behavioral ecology and Optimal Foraging Theory, however, more attention has been paid to target specialization. Drawing parallels between foraging and crime, Felson (2006) reframes this phenomenon as offenders' diet breadth. Similar to wolves hunting for deer, wild boars and hares (but rarely for livestock, see Lesniewicz and Perzanowski 1989), a particular shoplifter might be interested in stealing candy bars, power tools, or fur coats, but not for example, alcohol or make-up. Offenders thus decide on an operational range of preferred targets. To date, criminology lacks a formal theoretical framework that is able to explain why certain patterns of (target) specialization occur (Bernasco 2009). Conversely, the diet breadth of organisms is a widely studied behavioral strategy in behavioral ecology, in particular in Optimal Foraging Theory (OFT; Stephens and Krebs 1986).

OFT is a behavioural ecology framework that studies how organisms' behavioural patterns of seeking, selecting and processing resources necessary for survival are the result of evolutionary and ecological forces (Stephens and Krebs 1986). OFT contains a wide range of specific hypotheses, research methods, and tools of analysis that have been developed over the years (Stephens et al. 2007; Stephens and Krebs 1986), with many a priori predictions bearing close similarity to criminal decision-making (Bernasco 2009; Felson 2006; Johnson 2014; Johnson and Summers 2015). A growing number of studies have adopted a foraging perspective when exploring criminal activities, including studies regarding car theft (Brantingham 2013), residential burglary (Johnson et al. 2009; Townsley et al. 2016), and maritime piracy (Marchione and Johnson 2013).

Criminal target specialization is analogous to the prey selection model developed first by Charnov (1976b) and which has been used in criminology as a guiding principle to evaluate car thieves' target choices at the aggregate level (Badiora 2017; Brantingham 2013). The prey model predicts that specialization is the norm, and that offenders should only prefer a wider range when preferred targets become scarce. However, the algorithm assumes that, when operating in equal environments, offenders have similar target preferences and differences in target selection should generally be small. This assumption is not unique to optimal foraging models. In fact, it underlies many statistical and theoretical models used to study offender target decision-making, including the state of the art discrete spatial choice framework using the conditional logit model (Bernasco 2006; Bernasco and Block 2009; Bernasco and Nieuwbeerta 2005). 
Yet, offender characteristics such as impulsivity and cognitive abilities influence individual decisionmaking processes (Collins and Loughran 2017; Townsley et al. 2016), resulting in different target preferences. Similarly, in a study of LA car thieves, Brantingham (2013) considers the option that there exist several types of offenders, with each type having distinct target preferences, but ultimately assumes that the offender population under study largely consists of target generalists. Criminological research into offender decision-making increasingly tries to account for between-offender differences, for example in the study of variation in journeys to crime (Townsley and Sidebottom 2010; Van Daele 2010) or in burglary location choice (Frith et al. 2017; Townsley et al. 2016). These studies have shown that significant between-individual variation exists in offenders' target choices.

Similarly, studies in animal ecology are increasingly attentive to diet variation among members of the same species (e.g., Bolnick et al. 2003; Cantor et al. 2013; Tinker et al. 2012). A main finding of these studies is that populations of seemingly generalist species are in fact composed of highly specialized individuals. What looks like unspecialized foraging at the aggregate level is in fact the result of large heterogeneity between individual prey choices. ${ }^{1}$ Similarly, for a particular form of crime a wide range of targets might be recorded at the aggregate level, but individual offenders' choices might be narrow and specific.

Recent extensions of OFT allow individuals to differ in their prey preferences and diet breadth (Bolnick et al. 2003; Svanbäck and Bolnick 2005). Theoretical as well as empirical studies have found that there exist several alternative, highly structured ways in which individuals can subdivide the total population target choices (Araújo et al. 2011; Araújo et al. 2010; Bolnick et al. 2003). This is summarized in Fig. 1. A first possibility is that the population of offenders consists of both generalist and specialist offenders (see Fig. 1a). In this case, offenders rank target types similarly, but differ in their willingness to include inferior types in their target choices. As such, the choices of more selective offenders are nested in those of more versatile offenders. Second, the population may consist of highly specialized individuals, with little or no overlap in their target choices (see Fig. 1b). This is the case when target choice variation occurs completely at the individual level. Third, it is possible that individuals form clusters which prefer specific subsets of the population's target choices (see Fig. 1c).

[Insert Fig. 1 around here]

\section{GRAFFITI WRITERS' TARGET CHOICES}

Illicit graffiti is widespread in contemporary urban space, and has been an issue of public concern for several decades (e.g., Ley and Cybriwsky 1974). Considered art by some, the practice is often labeled by the general public and policy makers as mindless vandalism (Gomez 1992; Halsey and Young 2002). Graffiti presence is commonly viewed as a highly visible sign of disorder and decay, and is associated with increased fear of victimization (Doran and Lees 2005; Killias and Clerici 2000; McAuliffe 2012). Additionally, graffiti writing is directly linked to other forms of crime such as shoplifting of paint and materials, and violence between rivaling writers and crews (Ferrell and Weide 2010; Halsey and Young 2006). Drawing from the much-cited Broken Windows theory (Wilson and Kelling 1982), policy makers infer that graffiti writing that is left unchecked will attract more graffiti, and potentially other, more serious offenses. Experimental evidence furthermore shows that the presence of graffiti increases the occurrence of other forms of public disorder such as littering (Keizer et al. 2008). Graffiti causes great financial costs to society, estimated at CAD 4.5 million annually in Vancouver, Canada (Walker and

\footnotetext{
${ }^{1}$ For example, a population of the Thais melones (a species of snails) consumes over 20 different prey types, yet individuals consume no more than 1-5 types, frequently ignoring prey that other members of the same species prefer (West 1988).
} 
Schuurman 2015), while San Francisco (CA) city agencies spend over USD 20 million for graffiti abatement alone each year (Megler et al. 2014). National estimates are up to EUR 500 million in Germany (Leroch 2013) and over AUD 1.5 billion in Australia (Rollings 2008).

Graffiti is found on a wide array of surfaces and objects, leading both policy makers and the general public to assume that graffiti "seems to be written on everything" (Ferrell and Weide 2010, p. 54). In reality, the way in which writers select appropriate targets is the result of a complex interplay between informal subcultural guidelines, personal ethical and aesthetical considerations, and environmental opportunities (Ferrell and Weide 2010). Like other offenders, graffiti writers do not choose targets randomly (Halsey and Young 2006). There seem to be a number of universal, albeit loose, rules guiding graffiti writers' target selection (Ferrell 1993; Ferrell and Weide 2010; Halsey and Young 2006; van Loon 2014). Writers internalize these norms through social learning (Ferrell 1993; Halsey and Young 2006; Hannerz 2016) and by constantly evaluating and criticizing "one another's graffiti and graffitiwriting locations, in this way socializing novice writers into the process between discriminating between appropriate and inappropriate graffiti spots" (Ferrell and Weide 2010, p. 55).

Empirical research of (individual) graffiti writers' target choices remains scarce however. Studies are often ethnographic in nature (e.g., Ferrell 1993; Halsey and Young 2006). Such designs usually suffer from non-probabilistic sampling issues, typically focusing on prolific offenders (Townsley et al. 2015), which makes it difficult to infer the underlying rules guiding the total population of graffiti writers. Conversely, aggregate analyses (e.g., Haworth et al. 2013; Megler et al. 2014) do not allow to disentangle differences between individuals, a task that usually requires the use of data based on cleared offenses which might not be representative for all offenders (e.g., Townsley et al. 2016). Yet, the nature of graffiti offers an elegant solution to both issues. It is possible to link separate criminal events to the same individual and identify individuals via their pseudonym without having to rely on data based on cleared crimes (Macdonald 2001). It is difficult to overstate the advantages of being able to link offenses in a rather straightforward way. Given the low clearance rates of detected crimes in most Western countries (Vandeviver et al. 2015a), the use of data based on cleared offenses limits the generalizability and applicability of research results to crimes committed by unknown offenders. The use of data on graffiti writing circumvents this concern, since individuals leave their name tag as part of the offense.

Finally, the high prevalence of graffiti ensures sufficient data points (both aggregate and per individual). For example, Megler et al. (2014) used data on more than 59,000 graffiti incidents for 2009-2010 in San Francisco (CA), USA, Walker and Schuurman (2015) analyzed close to 7,000 illegal graffiti in Vancouver, Canada, while Haworth et al. (2013) reported on 12,000 incidents for a six-month period during 2010 in Sydney, Australia. Moreover, target specialization is more relevant for serial offending than for one-shot offenses. This is the case for graffiti since writers generally commit a large number of offenses, trying to saturate wide areas with their pseudonyms (Ferrell 1993).

\section{RESEARCH QUESTIONS}

Whether offenders differ in terms of target specialization has not been directly evaluated in criminological research. Given this observation we opt to investigate whether differences between offenders exist, and, if so, how these differences are structured. Drawing on the ecological literature discussed above, we therefore analyze the total population of graffiti writers' target choices and evaluate whether the total variation at the aggregate level is reflected at the individual level. Greater specialization should lead to increased between-individual variation in target choices (since not all targets are chosen at the individual level). This between-individual variation can arise in several ways, either due to nested (equal preferences, but differences in specialization) or distinct choices (different preferences) among individuals. This leads to the following research questions: 
1. How much between-individual variation in target choices exists?

2. Is the observed between-individual variation due to:

a. differences in nestedness (Fig. 1a)?

b. differences in writers' preferences, either at the individual level (Fig. 1b), or the group level (Fig. 1c)?

In line with the underlying assumption of previous studies that offender preferences are equal (see Target preferences versus target specialization), we employ the null hypothesis that individual graffiti writers have similar target preferences. Fluctuations should be small and attributable to chance.

\section{DATA}

Although several types of graffiti exist, the focus lies on name-based graffiti: graffiti which promotes an alias or moniker. Name-based graffiti remains the visually dominant form of graffiti in most contemporary Western cities (van Loon 2014). We can use each alias as a personal identifier. Pseudonyms are highly personal given the observation that copying or "biting" the name of others is discouraged within the subculture (Macdonald 2001, p. 70). Although some graffiti is done with permission by the owner or on so-called legal walls, we concentrate exclusively on illicit graffiti given that we want to study criminal foraging.

We used graffiti removal data recorded between January and December 2016 in Ghent, a medium-sized city in Belgium. In total, 768 requests for the removal of graffiti in 701 unique locations were extracted containing 2,652 observations of graffiti. These requests are the result of a mixture of reports made by or on behalf of both private $(N=580$, or $75.5 \%)$ and public property owners $(N=122$, or $15.9 \%)$, ${ }^{2}$ as well as the city administration proactively informing and encouraging property owners to file a request for removal. As such they cannot be interpreted as a complete dataset of all graffiti that occurred within the city limits. Instead, they reflect both administrative priorities, as well as spatial variation in the degree of acceptance or tolerance towards graffiti (Cresswell 1992). However, since administrative priorities focus on the administrative and cultural center, we restricted our analysis to the city center, a focus that is in line with previous research (Haworth et al. 2013). ${ }^{3}$ By limiting our research to the inner city, we have more confidence that a more unbiased picture emerges and that active writers had access to a more or less equal operating environment. We defined the city center as an area of approx. $8 \mathrm{~km}^{2}$ enclosed by an $11 \mathrm{~km}+$ long ring road which coincides with many of the city's historical borders.

We used the photographic documentation of the removed graffiti to manually code each individual graffito and register the used pseudonym (or when it was not possible to "read" the used tag, a threeletter code to use as an individual identifier) and the object the graffito was observed on. ${ }^{4}$ During coding, the target type classification was purposely kept specific (since types could always be grouped afterwards), resulting in 39 discrete types, which were manually grouped by the authors into 11 types

\footnotetext{
${ }^{2}$ For 66 (or 9.4\%) records no information about the property owner was included.

${ }^{3}$ Using the entire data set or just the observations that occurred within the city center did not lead to different conclusions, regardless of the target type classification used. The results presented here are those for the inner-city area using the coarse-grained target classification.

${ }^{4}$ To assess inter-rater reliability of graffiti coding, a 10\% random sample of graffiti removal records were coded by two additional independent observers. Intraclass correlation coefficients were calculated between the main observer and each additional observer for the number of identified graffiti $\left(\mathrm{ICC}_{1}=0.942, \mathrm{ICC}_{2}=0.942\right)$, pseudonyms $\left(\mathrm{ICC}_{1}=0.937, \mathrm{ICC}_{2}=0.917\right)$, graffiti types $\left(\mathrm{ICC}_{1}=0.792, \mathrm{ICC}_{2}=0.784\right)$, and target types $\left(\mathrm{ICC}_{1}=\right.$ $\left.0.804, \mathrm{ICC}_{2}=0.914\right)$, indicating good to excellent reliability (Portney and Watkins 2015).
} 
based on the observation that many categories overlap thematically. To illustrate, during coding the distinction was kept between different types of electrical transformer boxes, but given their overall similarity we decided to group them in one category afterwards. The same principle was applied for the other categories. Since it should at least be possible for within-individual variation to exist, we only retained individuals who were observed at least twice. ${ }^{5}$ This left us with 1,904 observations from 263 individuals, or $71.8 \%$ of all name-based graffiti that was registered in the city center.

\section{METHODS}

\section{Network analysis}

Ecological studies into animals' diet choices have increasingly used network analysis as an investigative tool regarding individual-level resource usage patterns (e.g., Araújo et al. 2008; Araújo et al. 2010; Cantor et al. 2013; Pires et al. 2011; Ramos-Robles et al. 2016; Tinker et al. 2012). A network consists of both nodes and edges. The first approach uses bipartite networks (BN), which means that network nodes are divided into two non-overlapping sets, with one set of nodes representing individuals, and the other set target types. The links between both sets of nodes are called edges, and reflect the choice of a particular target type. These edges are weighted by the number of targets of a particular type exploited by an individual (see Fig. 2a for a visualization of such a network representation). The second approach is based on the transformation of a bipartite network into an individual niche overlap network (IN), where nodes represent individuals and edges are weighted by the direct overlap in target choices among pairs of individuals (Araújo et al. 2008, see Fig. 2b).

\section{[Insert Fig. 2 around here]}

This approach is well suited for the research questions set out earlier, and combines a number of advantages compared with other tools of analysis. First, it is possible to examine the specific structure of how the total population choices are partitioned among individuals. These divisions correspond with specific network topologies, which can be quantified using a wide array of metrics (Tinker et al. 2012). Thus, this approach allows to associate different network topologies with differences in target specialization as well as target preferences. Second, no assumptions are being made about the relative importance of target attributes. Only the classification of targets into discrete types needs to be specified. Third, a network-based approach allows the specification of null networks which reflect different hypotheses about criminal target selection (Dormann et al. 2009). Finally, specialization and preferences are calculated relative to the aggregate target choices. This allows for meaningful comparisons across different crime types and geographic contexts with different opportunity structures.

\section{Empirical challenges}

In order to accurately estimate individual specialization, longitudinal data are preferred, where repeated observations of individual's target choices are recorded (Bolnick et al. 2002). Unfortunately, we are unable to verify the exact timing of the observations, since there is always an unknown amount of time between the production and subsequent reporting of graffiti. Therefore, our data are essentially crosssectional in nature, which requires a number of assumptions to be met (Araújo et al. 2011):

\footnotetext{
${ }^{5}$ Including offenders with less than two observations would bias the specialization metrics since one observation automatically implies a very narrow range. Excluding these not only makes sense intuitively, it also leads to a more conservative estimate of specialization. Nevertheless, we estimated all metrics for the entire sample as well, but this did not lead to substantially different conclusions. Only the results for the repeat offenders are presented here.
} 


\section{(i) There are multiple target choice observations per individual.}

This assumption was met by removing all individuals that were observed only once (see Data). However, the amount of observations varied between individuals (see Descriptive results). Even though the average number of observations was rather high, the majority of individuals were only observed twice. Since low sample sizes artificially inflate our estimates of individual specialization, we decided to correct for this by comparing our empirical values to those generated through a non-parametric, Monte Carlo resampling procedure (Araújo et al. 2011; Bolnick et al. 2002). In total, 999 simulated matrices were generated by assigning each individual graffiti events equal to their original observed number, via multinomial sampling (with replacement) from the population distribution. The population distribution contains only the data on individuals who were observed at least twice. For each simulated matrix, the discussed metrics are recalculated. The simulated matrices represent the null hypothesis that individuals stochastically sample items from a shared distribution. Thus, they represent the situation wherein any observed between-individual differences are small and attributable to chance. Observed values that fall outside of the 95\%-interval of generated values leads to rejection of the null hypothesis.

(ii) Multiple observations represent independent target choices.

It is possible that the observed target types are spatially dependent; i.e. that they cluster in space. Unfortunately, no data on the spatial distribution of target types were available, so we were unable to verify whether this assumption was met. Violations of this assumption may artificially inflate measures of target specialization. It is also important to note that the Monte Carlo procedure relies on this assumption. This means that, while we can use network analysis to assess target specialization, it is possible that some specialization is the result of the spatial distribution of target types in the environment. We can realistically assume that all individuals had access to roughly the same environment, so that any spatial clustering in targets will only influence the absolute degree of specialization. Given that our analysis focuses on between-individual variation in target choices and how these differences are structured, we are confident that our results are robust, despite the possibility that targets are spatially dependent.

(iii) The observed target choices are representative for the overall target preferences of the individual.

While we cannot be certain whether removed graffiti forms an accurate representation of graffiti writers' target preferences, graffiti removal records nevertheless "provide a useful surrogate for graffiti occurrence in the absence of resource intensive field surveys" (Haworth et al. 2013, p. 60). Since we restricted our analysis to the inner city, we have more confidence that our observations are representative for individuals' overall preferences, given the focus of rapid removal strategies on the administrative and cultural center, at least for their activities in the city center.

Additionally, the data contained only two observations for 97 individuals, while 214 individuals were observed fewer times than the number of target categories $(\mathrm{k}=11)$. For these individuals target specialization might be overestimated if the low amount of observations is a sampling artefact rather than the result of these individuals committing fewer offenses. However, we have no reason to believe this is the case. It is very plausible that some writers are more active than others. Finally, null models in combination with a Monte Carlo resampling procedure offset these issues (Araújo et al. 2011).

(iv) Comparisons between individuals must be made over a small spatial and temporal range. 
In order to minimize the influence of spatial and/or temporal variation, it is necessary to limit the spatial and temporal scales at which comparisons are made. The reason for this is that such variation might lead to over-estimation of between-individual variation. The geographic focus was limited to the inner city, an area of $8 \mathrm{~km}^{2}$. The data span one year, because this ensures sufficient data points per individual, while also removing seasonal influences. The trade-off is that some variation found between individuals might be caused by changes in the environment over time. However, since the structure of target specialization is the focus of our analyses, rather than the underlying cause, the impact of any spatial-temporal variation would be minimal.

\section{Metrics}

Individual target specialization. The degree of target specialization at the population-level and for each individual are calculated using Simpson's index (SI), an ecological measure of diversity (Simpson 1949). This index is an indicator for the amount of different targets one can discern, and how evenly observations are distributed among those target types. We used a correction for small sample sizes as proposed by Hunter and Gaston (1988), and calculated SI as:

$$
S I=1-\frac{1}{N(N-1)} \sum_{S=1}^{S} n_{j}\left(n_{j}-1\right)
$$

where $\mathrm{N}$ stands for the total amount of tags, $\mathrm{S}$ for the amount of different target types, and $n_{j}$ stands for the amount of tags on target $s$. The value is an estimation (for samples without replacement) of the probability that a random pair of tags are on different targets. As sample size grows, the formula approaches Simpson's index. The larger the coefficient, the smaller the chance that two observations contain the same target type. Thus, given the extreme case where each observation is on a different target type, SI would be equal to 1 , since there is a $100 \%$ probability that two random observations are on different target types. Conversely, if only one target type is observed for the entire population, SI equals to zero. This metric gives us an idea about the overall target specialization at the aggregate level, and by calculating SI for each individual, at the individual level as well.

In addition, we partitioned the total variance in target choices at the aggregate level as described in Roughgarden (1979). This calculation separates the total variance in target choices (TNW) into two components: 1) the variance within individuals (within-individual component; WIC), and 2) the variance between individuals (between-individual component, BIC). ${ }^{6}$ The ratio between WIC and $T N W$ approaches 1 when all individuals select the total range of target types, and smaller values indicating decreasing inter-individual overlap in target choices, and hence, increased target specialization. It is calculated as:

$$
\frac{W I C_{s}}{T N W_{s}}=\frac{\sum_{i=1}^{I} p_{i \cdot}\left(-\sum_{j=1}^{J} p_{i j} \ln \left(p_{i j}\right)\right)}{-\sum_{j=1}^{J} q_{j} \ln \left(q_{j}\right)}
$$

where $p_{i}$ is the proportion of observations of individual $i$ in the total sample, $p_{i j}$ is the proportion of target type $j$ within the observations of individual $i$, and $q_{j}$ is the proportion of observations containing target type $j$ in the total sample. WIC / TNW can be interpreted as the proportion of the variance in target

\footnotetext{
${ }^{6}$ Since target choices are quantified as the frequency of distinct target types observed in offenders' choices, the
} Shannon entropy is used as a proxy for variance (Roughgarden 1979, p. 510). 
choices at the aggregate level that is the result of differences within individuals, as opposed to differences between individuals. However, when discussing the metric we will refer to $1-W I C / T N W$, interpreted as the proportion of variance in target choices at the aggregate level resulting from differences between individuals. Thus, higher values indicate greater between-individual variation.

We also calculated the average density of connections in the IN network using the $E$-index of Araújo et al. (2008) as the average pairwise dissimilarity of individual target choices. It is calculated as follows. First, for each pair of individuals $i$ and $j$ the amount of overlap in target choices $w_{i j}$ is calculated as:

$$
w_{i j}=1-0.5 \sum_{k=1}^{K}\left|p_{i k}-p_{j k}\right|
$$

where $p_{i k}$ and $p_{j k}$ are the proportions of target type $k$ in the observations of individual $i$ and $j$, respectively. This is the IN network discussed earlier. Second, the average network density of connections $\breve{O}$ is calculated by taking the sum of the overlap measures and dividing this by the number of edges in a completely connected network of $n$ individuals:

$$
\breve{O}=\frac{\sum w_{i j}}{n(n-1)}
$$

Since $\breve{O}$ can also be interpreted as the average pairwise similarity in a network, we can subtract $\breve{O}$ from 1 to obtain a measure of between-individual dissimilarity. Finally, E can be calculated as:

$$
E=1-\breve{O}
$$

This metric varies from 0 (all individuals choose the same target types, meaning the population consists completely of target generalists) to 1 (all individuals' target choices differ completely).

Nestedness. A nestedness metric is used to evaluate whether the target choices of more specialized individuals are nested in those of more versatile individuals. Nestedness in binary bipartite networks (see Fig. 1a) is commonly calculated using the nestedness metric based on two properties: overlap and decreasing fill (NODF; Almeida-Neto et al. 2008). We take a binary matrix with $m$ rows and $n$ columns, where row $i$ is located above row $j$, and column $k$ is located to the left from column $l$. First, we calculate $M T$ as the marginal total of any row or column. For any pair of rows/columns $i$ and $j, D F_{i j}$ will be equal to 100 if $M T_{j}$ is lower than $M T_{i}$. Conversely, $D F_{i j}$ will be equal to 0 if $M T_{j}$ is greater or equal to $M T_{i}$. For rows/columns, paired overlap $\left(\mathrm{PO}_{k l}\right)$ is simply the proportion of 1 's in a given row/column $l$ that are located at the same row/column positions to those in a row/column $k$. For any left-to-right column pair and, similarly, for any up-to-down row pair, there is a degree of paired nestedness $\left(N_{\text {paired }}\right)$ as zero if $D F_{\text {paired }}$ is zero, and $P O$ if $D F_{\text {paired }}$ is 100 .

From the paired degrees of nestedness for $n$ columns and $m$ rows, we can calculate a measure of nestedness among columns $\left(N_{c o l}\right)$ and among rows $\left(N_{\text {row }}\right)$ by taking the average of all paired values of columns and rows, respectively. Finally, the measure of nestedness for the whole matrix is calculated as the weighted average of $N_{c o l}$ and $N_{\text {row }}$. To summarize, whether a particular row or column is nested within another is evaluated: 1) by checking if the marginal total of the row/column is lower than that of the row/column its being compared to (i.e. decreasing fill), and 2) if so, by calculating the overlap between those pair of rows/columns. While NODF is limited to binary (absence-presence) matrices, an extension for weighted networks has also been developed using a similar approach (WNODF; Almeida- 
Neto and Ulrich 2011). Both metrics range from 0 (no nestedness) to 100 (perfect nestedness). Smaller values are indicative of a modular network (see below). Since the value of (W)NODF depends on the order of rows and columns in the matrix, the matrix is sorted by decreasing rows and columns degrees before the procedure, so that rows with higher degrees are in the top of the matrix and columns with higher degrees are in the left. This is the most commonly used sorting procedure since it maximizes the value of NODF (Beckett et al. 2014).

Distinct preferences and network modularity. Distinct preferences are associated with highly modular networks: networks characterized by clusters of individuals around shared target types (see Figs. $1 \mathrm{~b}$ and 1c). Such clustering will occur when the total population can be divided into discrete groups around shared subsets of target types with little to no overlap between clusters. Translated to graffiti writing, it is possible that there exist distinct groups of writers that prefer particular target types.

Network modularity in the IN network is measured using the relative degree of clustering $C_{W S}$ proposed by Araújo et al. (2008), which compares the overall density of connections in the network $(\breve{O})$ to the density of connections around individual nodes. First, individual clustering coefficients $C_{w_{i}}$ are calculated as the combined measure of the number and weight of the edges around individual $i$ and among the nodes directly connected to it. We used the weighted clustering coefficient proposed by Saramäki et al. (2007) to quantify how much weight is present in the neighborhood of the node. Next the average of these individual clustering coefficients $C_{w}$ is calculated, which is approximately equal to $\breve{O}$ in a totally random network, so that it is necessary to correct for this by:

$$
C_{W S}=\frac{\left(C_{w}-\breve{O}\right)}{\left(C_{w}+\breve{O}\right)}
$$

so that $C_{W S}$ will approximate 0 in a totally random network. Negative values indicate that all individuals prefer distinct (combinations of) target types among each other (Fig. 1b). Positive values indicate clustering of individuals around shared target types (Fig. 1c).

Additionally, we calculated the modularity $M$ for BN to evaluate whether individuals cluster around shared target types (Guimerà et al. 2007). For a given partition of the nodes of a network into modules, the modularity $M$ of this partition is:

$$
M=\sum_{s=1}^{N_{M}}\left[\frac{l_{s}}{L}-\left(\frac{d_{s}}{2 L}\right)^{2}\right]
$$

where $N_{M}$ is the number of modules, $L$ is the number of edges in the network, $l_{s}$ is the number of edges between nodes in module $s$, and $d_{s}$ is the sum of the degrees of the nodes in module $s$. A simulated annealing algorithm is used to find the partitioning that yields the greatest degree of modularity (Guimerà and Amaral 2005a; b). This approach identifies the partitioning that has many within-module interactions, and few between-module interactions. High values indicate clustering of individuals around shared target types (Fig. 1c). This would indicate that there exist distinct groups of graffiti writers that seem to prefer the same target types to write on.

Finally, given that it is difficult to interpret the absolute values of $C_{W S}$ and $M$, the empirical values are compared to those generated through the Monte Carlo resampling procedure described above. 


\section{RESULTS}

\section{Descriptive results}

On average, each individual committed 7.2 offenses $(s d=11.6)$. The data show a highly uneven distribution of offenses among individuals. 35 out of 263 individuals (or 13.3\%) account for more than $50 \%$ of all registered graffiti in the city center $(\operatorname{Gini}(G)=0.31)$. This is in line with the common observation that crime is concentrated among a small group of offenders (Martinez et al. 2017). The observations are largely concentrated on a small number of target types, with the top three types accounting for $87.6 \%$ of all name-graffiti $(G=0.29)$. Most registered graffiti occurs on buildings (incl. doors and windows, $N=1135$ or $59.6 \%$, see table 1 for the distribution of all target types), followed by electrical transformer boxes $(N=403 ; 21.2 \%)$ and under bridges and overpasses $(N=$ $129 ; 6.8 \%)$. Each individual targeted 2.1 different types on average $(s d=1.3)$.

The most common form of observed graffiti is the tag $(N=1752 ; 92.0 \%)$ : simple signature-like scribbles designed for fast execution using limited resources. The remaining graffiti consist of technically complex (master)pieces $(N=9 ; 0.5 \%)$ and illustrations $(N=72 ; 3.8 \%)$. Finally, the throw-up $(N=71 ; 3.7 \%)$ occupies the middle ground between tags and pieces, usually consisting of two-dimensional bubble style letters.

[Insert table 1 around here]

We obtain a first estimate of the degree of target specialization by calculating Simpson's Index. SI demonstrates that the probability that two tags are on different target types is approximately $60 \%$ (SI = 0.593). However, the total diversity in target choices at the aggregate level is not entirely reflected at the individual level $(\overline{S I}=0.385, s d=0.371)$. This indicates that, on average, individual target specialization is significantly lower when compared to the aggregate level $(t(262)=-9.08, p<$ 0.01).This is in line with the observation that most individuals target only a small amount of different objects. In addition, for 110 individuals no variation in target types was recorded, so SI is equal to zero. Simpson's index was only weakly correlated with the number of offenses per individual $(r(261)=$ $.18, p<0.01)$, indicating that the measurement of target specialization is minimally influenced by the number of observations.

[Insert figure 3 around here]

\section{Variance partitioning and network analysis}

The BN and IN networks are constructed and subsequently subjected to analysis. First, the total variation in target choices is separated into a within- and between-individual component, which allows the calculation of the proportion of variation at each level. An estimated $40.4 \%$ of the total variation in target choices is due to differences between individuals, rather than within individuals $($ WIC $/ T N W=$ 0.596, NULL $\left._{95 \%}=[0.674,0.764], p=0.001\right)$.

In addition, the network parameter $E$ indicates significant pairwise dissimilarity between individual writers' target choices $\left(E=0.500, N U L L_{95 \%}=[0.406,0.466], p=0.001\right)$. This indicates that target choices only partly overlap between individuals, and less than assumed under the null hypothesis that individuals have the same underlying target preferences. Both WIC /TNW and the network parameter $E$ thus indicate significant between-individual variation in target choices.

Next, we estimate whether the between-individual variation in target choices is due to nestedness (where the choices of more specialized individuals are contained in those of less specialized ones) or modularity (reflecting different preferences). First, the degree of nestedness is calculated using both the weighted 
and unweighted NODF measure. We find that both values are lower than expected if all individuals preferred the same target types $\left(N O D F=45.49, N U L L_{95 \%}=[51.16,57.58], p=0.001 ; W N O D F=\right.$ $\left.30.29, N U L L_{95 \%}=[32.63,37.19], p=0.001\right)$. These results show a significantly anti-nested pattern, which is indicative of a modular network.

Second, we calculate the degree of modularity in the resource network. Both the weighted clustering coefficient $\left(C_{W S}=0.044, N U L L_{95 \%}=[-0.003 ; 0.011], p=0.001\right)$ as well as Guimerà's modularity $\left(M=0.179, N U L L_{95 \%}=[0.095 ; 0.121], p=0.001\right)$ indicate significant clustering of individuals around shared target types. The simulated annealing algorithm partitioned the 263 individuals into 39 clusters, of which 29 consist of just one individual pseudonym (thus containing $11.03 \%$ of individuals). The observations fit a pattern that is a mix between a population consisting of highly specialized individuals (see Fig. 1b) and clusters of individuals that prefer the same subsets of targets (see Fig. 1c).

In addition, we compare the within- and between-module rank ordering of target types by calculating Spearman's rank correlation coefficient between each pair of individuals, resulting in 34,453 coefficients (15,526 coefficients between individuals that belong to the same cluster; 18,897 coefficients between individuals that belong to different clusters). The median rank correlation between individuals in the same cluster $(M d n=0.752)$ is significantly higher than between modules $(M d n=$ 0.380 ; Mann - Whitney $U=3.515 \times 10^{7}, p<0,001$ ). This indicates that individuals that prefer the same targets also seem to hit the same types more often.

[Insert table 2 around here]

\section{DISCUSSION}

The purpose of the research reported here was to simultaneously evaluate urban graffiti writers' target preferences and degree of specialization, thus adding both to the limited scholarship on offender target specialization and the few environmentally-oriented studies on graffiti writers' decision-making. Importantly, the focus on graffiti allowed us to circumvent the key weakness of criminological research of solely relying on cleared crime data, and thus limiting the applicability of research results, while also allowing to link separate criminal events to the same offender. Graffiti removal records were analyzed using a network-based approach inspired by empirical research in animal ecology.

Based on these results, we established that graffiti writers' individual target choices significantly differ amongst each other. Around $40 \%$ of the total variation in target choices was due to differences between individuals. Although we observed a broad range of targets at the aggregate level, individual graffiti writers exhibited distinct preferences for just a few specific targets. Thus, the aggregate target choices of graffiti writers appear versatile and broad, whereas their individual choice behavior is severely restricted. We did not find evidence of a nested choice pattern whereby the choices of more specialized writers are a subset of more versatile writers. Instead, the network topology showed significant clustering of individuals around shared target types. A large part of the variation in observed target choices at the population-level was thus the result of (groups of) individuals specializing on subsets of the observed targets and potentially competing for shared targets. We found evidence for both the existence of groups of graffiti writers around shared preferences, as well as individuals having distinct target preferences. It is important to note, however, that we do not imply that the observations of individuals belonging to the same cluster also cluster in space, though they may if target types cluster in space. Instead, we found that the total population of graffiti writers can be subdivided in groups that prefer the same subsets of targets to write on. The reported values are in line with those found in studies of animal prey choices (e.g., Tinker et al. 2012), where greater between-individual variation and clustering are observed as the abundance of preferred prey in the environment declines (Araújo et al. 
2008). These similarities further suggest that similar ecological patterns might underlie crime patterns (e.g., Brantingham 2016; Felson 2006).

Contrary to Brantingham's (2013: 10) assertion that "unspecialized foragers" probably "greatly outnumber the specialists, making the latter practically invisible in aggregate data", our results support the opposite, at least for graffiti writing. These results do not fit the popular image of the opportunistic graffiti writer who tags indiscriminately. Some do, but the majority of writers stick to a handful of different target types. Our observations indicate that a large degree in variation in target choices at the aggregate level does not need to be reflected at the individual level. Instead, a seemingly generalist population without apparent target preferences may in fact consist of highly specialized individuals with distinct target preferences. Assuming that aggregate patterns accurately reflect individual patterns would constitute a logical fallacy (Robinson 1950), with serious implications for both research and policy initiatives. Although it is impossible to extrapolate these findings to other offense types, our results are in line with the observation of Townsley et al. (2016) and Frith et al. (2017) that significant preference variation exists between burglars, which suggests that the observed patterns likely hold for other crime types as well.

Our observations might be rooted in graffiti subculture customs. Writers compete for high-valued targets and are discouraged from tagging directly next to reputable writers (Ferrell and Weide 2010). This might drive specialization and between-individual variation if graffiti writers try to avoid targets that are already claimed by more reputable writers, increasing differences between individual choices. Thus, the observed clusters of offenders might reflect differences in subcultural status when targets are scarce. Verifying this would require a more complex, spatio-temporal analysis accounting for the available targets in the area, preferably containing offender characteristics, which was not possible with the available data.

Similarly, animal ecology studies find increased between-individual variation in areas where competition between members of the same species is high (Araújo et al. 2008; Svanbäck et al. 2008; Tinker et al. 2012). To illustrate, an experimental study by Svanbäck and Bolnick (2007) found that a population of stickleback consumed a larger diversity of prey types as competition increased, via greater between-individual variation. Optimal Foraging Theory suggests that, in order to alleviate competitive pressures with member of the same species, animals resort to different prey types (Svanbäck and Bolnick 2005). Like sticklebacks, graffiti writers might avoid competition through individual target specialization, by choosing only a subset of target types that is sufficiently different from others' target choices.

Behavioral ecology can furthermore serve as a rich source of hypotheses regarding potential underlying mechanisms at the individual level. OFT suggests that differences in individual abilities to search, handle and process prey should lead to different target preferences (Svanbäck and Bolnick 2005). For example, between-individual variation among members of the cabbage butterfly is the result of individuals having different search images, affecting individual's search efficiency for certain flower species (Lewis 1986). Similarly, more experienced graffiti writers might be more efficient in their search and handling of particular target types. Thus, criminal expertise might be an important factor in explaining differences in target preferences and specialization (e.g., Nee et al. 2015). Additionally, risk aversion might be an important individual determinant of target preferences. Wilson (1998) suggests that populations might consist of risk-prone and risk-averse individuals, each with different diet assembly rules, possibly indicating that individuals optimize different criteria. For example, instead of maximizing benefits, some offenders prefer targets that are farther away in an effort to minimize the risk of getting caught (Vandeviver and Bernasco 2019; Vandeviver et al. 2015b). Target displacement in the form of changing preferences and in- or decreasing specialization may occur in the face of increasing police effort. If 
individual differences in risk aversion exist, differences in individuals' target choices might become more pronounced as the risk of getting caught rises. Finally, differences in social status might restrict access to preferred resources (Bolnick et al. 2003). For example, dominant surfperch will actively monopolize their preferred prey type, leaving subordinate individuals to rely on lower-quality prey (Holbrook and Schmitt 1992). This would imply that novice graffiti writers are discouraged from choosing certain target types if higher-status writers already pursue those. A potential research avenue would thus be to assess whether target specialization and preferences are related to individual characteristics such as experience, risk aversion, subcultural status and/or group membership.

In addition, local regulatory regimes influence writers' target and location choices (van Loon 2014). Within the study area, as within many Western cities, rapid removal is seen as one of the most important deterrents for graffiti writing (Halsey and Young 2002). Since visibility and exposure are important characteristics of desired graffiti targets (Austin 2001; Ferrell and Weide 2010; Gomez 1992; Kindynis 2017; Megler et al. 2014; Walker and Schuurman 2015), rapid removal strategies try to limit the benefits for writers. OFT suggests that differences between individuals become more pronounced when resources become scarce (Svanbäck and Bolnick 2005). This implies that large differences between individuals are more likely to be found in environments with few targets and a large number of active offenders. Although we cannot verify this assumption, it is possible that a reduction in benefits of highranked targets leads to increased diversification among individuals, as predicted by OFT.

Finally, our findings suggest that criminal target selection studies preferably account for individual differences. For example, a large body of the (spatial) target selection literature is built upon the conditional logit model (Bernasco 2010; Bernasco and Block 2009; Bernasco and Nieuwbeerta 2005), which assumes that target preference variation is systematic and contingent upon measured offender characteristics. When this assumption is not met, it undermines our confidence in the obtained results (Townsley et al. 2016). While the mixed logit approach counters some of the weaknesses in the conditional logit model (Train 2009), the model has some issues of its own in terms of estimation, the choice of distribution function, and the demands it imposes on the data (Hensher and Greene 2003; Hess and Train 2017). The network-based approach described in this research article, although different in the nature of the questions it addresses, might provide an alternative to further explore betweenindividual differences in target selection from within a unified framework. The estimation of its parameters is fairly straightforward and needs little specification aside from the target types. We believe it might be especially well-suited for problems where it is not possible or not feasible to directly measure the costs and benefits associated with particular target types. However, contrary to the discrete spatial choice framework, the network-based approach is not spatial. Geographic information can currently not be explicitly included in the analysis.

Future situational crime prevention initiatives may benefit from our results as well and may need to consider that the population of offenders might consist of different offender subgroups with different target strategies. Each of these groups might require different prevention strategies. Specifically for graffiti writing, writers might adapt to rapid removal strategies by deploying distinct target strategies. Some authors have already noted some of the potentially unwanted consequences of this policy since rapid removal pushes graffiti writers to more "quick and dirty" work which is less pleasing to the public eye (Walker and Schuurman 2015). As Ferrell and Weide (2010, p. 54) put it: "[f] rom a graffiti writer's perspective, a spot that won't last long doesn't merit serious artistic investment — but then again, a spot with high traffic and visibility isn't to be abandoned, either". Thus, graffiti abatement programs not only shift the form of graffiti, but possibly also on what targets it is found.

It is important to note some of the limitations of this study. First, it is unclear whether removed graffiti forms an accurate representation of all urban graffiti writing. Just as with all forms of criminal behavior, 
underreporting and underregistration hampers our ability to extrapolate our findings. Nevertheless, graffiti removal records are still a useful data source when direct observation is not feasible (Haworth et al. 2013, p. 60). We argue that the ability to study unknown offenders in a straightforward manner offsets these disadvantages.

Second, we assumed that we could equate pseudonyms with individuals. Although this is in line with legal practice (Leroch 2013), this assumption is challenged by the possibility that writers use multiple aliases, or frequently change their preferred alias in order to throw off the authorities (Ferrell 1993). However, according to a local graffiti youth organization active in the study area the use of multiple pseudonyms is a rare practice (Vanhoenacker and Bosschaert 2011). At the very least, it seems warranted to assume that writers' target choices are consistent across different aliases.

Finally, graffiti writers' target choices were examined from the individual's perspective for analytical clarity. In reality, deciding where to offend is often complicated because of co-offending, possibly resulting in different decision outcomes (e.g., Lammers 2018). This issue is not unique to this study. Even if data based on cleared offenses are used, they might not accurately reflect co-offending processes given that caught offenders are reluctant to inform on their accomplices. However, most of the observed graffiti were tags (ca. 92\%), which are largely the product of solitary offending (Macdonald 2001). Cooffending might play a bigger role for more complex forms of graffiti, where writing is divided into several sub-tasks (e.g., filling out of large spaces in a piece outlined by another, usually more experienced, writer), and a split between handling and looking out for passers-by, police, private security, or property owners (Ferrell 1993).

Further research could extend the network-based approach to other types of (serial) offending and different contexts. Doing so would offer additional insight into the occurrence of common patterns of differing preferences and/or specialization across multiple geographic regions, cultures and offense types.

Second, previous research suggests that exposure and visibility are important characteristics of good targets and locations (e.g., Ferrell and Weide 2010). It is perhaps fruitful to directly quantify both aspects as a result of the street layout using space syntax methods (e.g., Frith et al. 2017; Summers and Johnson 2017) and visibility graph analysis (Turner 2001). These metrics can subsequently be related to the prevalence of graffiti.

Third, further ethnographic research could be conducted to frame these results, to identify other aspects underlying graffiti writers' decision-making, and to clarify the circumstances under which certain targets are preferred over others. Qualitative research so far has primarily investigated the meanings and motivations associated with graffiti writing (e.g., Halsey and Young 2006), at the expense of more environmentally oriented research. Yet, relevant observations and interpretations based on offender accounts are crucial to fill in the formal ecological models from which we draw inspiration (Bernasco 2009). At the same time, theoretical and empirical findings from behavioral ecology may provide new research questions for qualitative researchers interested in offender decision-making.

To conclude, the aim of this research was to simultaneously evaluate individual differences in target preferences and specialization. The results indicate that individual graffiti writers differ greatly. Furthermore, the network topology revealed that the total population of graffiti writers consists of several subtypes, each with their own target preferences. What seemed like unspecialized targeting at the aggregate level is in fact the result of individuals choosing only a few, but distinct, target types. These results suggest that assuming that between-individual differences in target preferences are 
negligible might not be warranted (at least for graffiti writing) and illustrate the need to account for differences between offenders.

This study demonstrates that behavioral ecology can both inspire criminological research directions and offer a formal framework to improve our understanding of offender decision-making. The present study was informed by the large body of literature on optimal foraging, demonstrating that tools developed for the study of animal foraging decisions show great potential for application to criminal decision problems. The similarity of these findings to those in animal ecology studies is noteworthy and further supports the idea that crime patterns might correspond to common ecological patterns. 


\section{REFERENCES}

Almeida-Neto M and Ulrich W. (2011) A straightforward computational approach for measuring nestedness using quantitative matrices. Environ Modell Softw 26: 173-178

Almeida-Neto M, Guimarães P, Guimarães PR, Loyola RD and Ulrich W. (2008) A consistent metric for nestedness analysis in ecological systems: reconciling concept and measurement. Oikos 117: $1227-1239$

Araújo MS, Bolnick DI and Layman CA. (2011) The ecological causes of individual specialisation. Ecol Lett 14: 948-958

Araújo MS, Guimarães PR, Svanbäck R, Pinheiro A, Guimarães P, Reis SFd and Bolnick DI. (2008) Network analysis reveals contrasting effects of intraspecific competition on individual vs. population diets. Ecology 89: 1981-1993

Araújo MS, Martins EG, Cruz LD, Fernandes FR, Linhares AX, Dos Reis SF and Guimarães PR. (2010) Nested diets: a novel pattern of individual-level resource use. Oikos 119: 81-88

Austin J. (2001) Taking the train: How graffiti art became an urban crisis in New York City. New York, Columbia University Press

Badiora AI. (2017) Ecological Theories and Spatial Decision Making of Motor Vehicle Theft (MVT) Offenders in Nigeria. Journal of Applied Security Research 12: 374-391

Beckett SJ, Boulton CA and Williams HT. (2014) FALCON: a software package for analysis of nestedness in bipartite networks. F1000Research 3

Bernasco W. (2006) Co-offending and the choice of target areas in burglary. J Invest Psychol Off 3: $139-155$

Bernasco W. (2009) Foraging strategies of homo criminalis: Lessons from behavioral ecology. Crime Patterns and Analysis 2: 5-16

Bernasco W. (2010) Modeling micro-level crime location choice: Application of the discrete choice framework to crime at places. J Quant Criminol 26: 113-138

Bernasco W and Block R. (2009) Where offenders choose to attack: A discrete choice model of robberies in Chicago. Criminology 47: 93-130

Bernasco W and Nieuwbeerta P. (2005) How do residential burglars select target areas? A new approach to the analysis of criminal location choice. Brit J Criminol 45: 296-315

Bolnick DI, Svanbäck R, Fordyce JA, Yang LH, Davis JM, Hulsey CD and Forister ML. (2003) The ecology of individuals: incidence and implications of individual specialization. Am Nat 161: $1-28$

Bolnick DI, Yang LH, Fordyce JA, Davis JM and Svanbäck R. (2002) Measuring individual-level resource specialization. Ecology 83: 2936-2941

Brantingham PJ. (2013) Prey selection among Los Angeles car thieves. Crime Science 2: 1-11

Brantingham PJ. (2016) Crime Diversity. Criminology 54: 553-586

Cantor M, Pires MM, Longo GO, Guimarães PR and Setz EZF. (2013) Individual variation in resource use by opossums leading to nested fruit consumption. Oikos 122: 1085-1093

Charnov EL. (1976a) Optimal foraging, the marginal value theorem. Theor Popul Biol 9: 129-136

Charnov EL. (1976b) Optimal foraging: attack strategy of a mantid. Am Nat 110: 141-151

Clarke RV. (1992) Situational crime prevention : successful case studies. New York (N.Y.) : Harrow and Heston

Clarke RV and Harris PM. (1992) A rational choice perspective on the targets of automobile theft. Crim Behav Ment Heal 2: 25-42

Cohen LE and Felson M. (1979) Social change and crime rate trends: A routine activity approach. Am Sociol Rev: 588-608

Collins ME and Loughran TA. (2017) Rational choice theory, heuristics, and biases. In: Bernasco W, Elffers H and Van Gelder J-L (eds) The Oxford Handbook of Offender Decision Making. New York, Oxford University Press, 10-23

Cornish DB and Clarke RV. (1986) The reasoning criminal : rational choice perspectives on offending. New York (N.Y.) : Springer

Cresswell T. (1992) The crucial 'where'of graffiti: a geographical analysis of reactions to graffiti in New York. Environ Plann D 10: 329-344 
Doran BJ and Lees BG. (2005) Investigating the spatiotemporal links between disorder, crime, and the fear of crime. Prof Geogr 57: 1-12

Dormann CF, Fründ J, Blüthgen N and Gruber B. (2009) Indices, graphs and null models: analyzing bipartite ecological networks. The Open Ecology Journal 2

Felson M. (2006) Crime and nature. Thousand Oaks (Calif.), Sage

Ferrell J. (1993) Crimes of style : urban graffiti and the politics of criminality. New York (N.Y.) : Garland

Ferrell J and Weide RD. (2010) Spot theory. City 14: 48-62

Frith MJ, Johnson SD and Fry HM. (2017) Role of the Street Network in Burglars' Spatial DecisionMaking. Criminology 55: 344-376

Giraldea L-A and Pyke GH. (2019) Group Foraging. In: Choe J (ed) Encyclopedia of Animal Behavior (Second Edition). Oxford, Academia Press, 191-200

Gomez MA. (1992) The writing on our walls: Finding solutions through distinguishing graffiti art from graffiti vandalism. U Mich JL Reform 26: 633

Guimerà R and Amaral LAN. (2005a) Cartography of complex networks: modules and universal roles. J Stat Mech-Theory E 2005: P02001

Guimerà R and Amaral LAN. (2005b) Functional cartography of complex metabolic networks. Nature 433: 895

Guimerà R, Sales-Pardo M and Amaral LAN. (2007) Module identification in bipartite and directed networks. Phys Rev E 76: 036102

Halsey M and Young A. (2002) The meanings of graffiti and municipal administration. Aust Nz J Criminol 35: 165-186

Halsey M and Young A. (2006) 'Our desires are ungovernable'Writing graffiti in urban space. Theor Criminol 10: 275-306

Hannerz E. (2016) Scrolling down the line-a few notes on using Instagram as point of access for gra ti research. Urban Creativity Scientific Journal: 37

Haworth B, Bruce E and Iveson K. (2013) Spatio-temporal analysis of graffiti occurrence in an innercity urban environment. Appl Geogr 38: 53-63

Hensher DA and Greene WH. (2003) The mixed logit model: the state of practice. Transportation 30: $133-176$

Hess S and Train K. (2017) Correlation and scale in mixed logit models. Journal of Choice Modelling 23: $1-8$

Holbrook SJ and Schmitt RJ. (1992) Causes and consequences of dietary specialization in surfperches: patch choice and intraspecific competition. Ecology 73: 402-412

Hunter PR and Gaston MA. (1988) Numerical index of the discriminatory ability of typing systems: an application of Simpson's index of diversity. J Clin Microbiol 26: 2465-2466

Jacobs B. (2010) Serendipity in robbery target selection. Brit J Criminol 50: 514-529

Jacobs BA. (2000) Robbing drug dealers: Violence beyond the law. New Brunswick (N.J.), Transaction Publishers

Johnson SD. (2014) How do offenders choose where to offend? Perspectives from animal foraging. Legal Criminol Psychol 19: 193-210

Johnson SD and Summers L. (2015) Testing ecological theories of offender spatial decision making using a discrete choice model. Crime Delinquency 61: 454-480

Johnson SD, Summers L and Pease K. (2009) Offender as forager? A direct test of the boost account of victimization. J Quant Criminol 25: 181-200

Keizer K, Lindenberg S and Steg L. (2008) The spreading of disorder. Science 322: 1681-1685

Killias M and Clerici C. (2000) Different measures of vulnerability in their relation to different dimensions of fear of crime. Brit J Criminol 40: 437-450

Kindynis T. (2017) Bomb alert: Graffiti writing and urban space in London. The British Journal of Criminology

Krebs JR, Davies NB and Parr J. (1996) An introduction to behavioural ecology. Oxford : Blackwell

Lammers M. (2018) Co-offenders' crime location choice: Do co-offending groups commit crimes in their shared awareness space? Brit J Criminol 58: 1193-1211

Langton SH and Steenbeek W. (2017) Residential burglary target selection: An analysis at the property-level using Google Street View. Appl Geogr 86: 292-299 
Leroch MA. (2013) Punishment as defiance: deterrence and perverse effects in the case of expressive crime. CESifo Econ Stud 60: 581-598

Lesniewicz K and Perzanowski K. (1989) The winter diet of wolves in Bieszczady Mountains. Acta Theriologica 34: 373-380

Lewis AC. (1986) Memory constraints and flower choice in Pieris rapae. Science 232: 863-865

Ley D and Cybriwsky R. (1974) Urban graffiti as territorial markers. Ann Assoc Am Geogr 64: 491505

Light R, Nee C and Ingham H. (1993) Car theft: The offender's perspective. HM Stationery Office

Macdonald N. (2001) The graffiti subculture: Youth, masculinity and identity in London and New York. Springer

Marchione E and Johnson SD. (2013) Spatial, temporal and spatio-temporal patterns of maritime piracy. J Res Crime Delinq 50: 504-524

Marshall HH, Carter AJ, Ashford A, Rowcliffe JM and Cowlishaw G. (2013) How do foragers decide when to leave a patch? A test of alternative models under natural and experimental conditions. J Anim Ecol 82: 894-902

Martinez NN, Lee Y, Eck JE and SooHyun O. (2017) Ravenous wolves revisited: A systematic review of offending concentration. Crime Science 6: 10

McAuliffe C. (2012) Graffiti or street art? Negotiating the moral geographies of the creative city. J Urban Aff 34: 189-206

Megler V, Banis D and Chang H. (2014) Spatial analysis of graffiti in San Francisco. Appl Geogr 54: 63-73

Nee C and Taylor M. (1988) Residential burglary in the Republic of Ireland: A situational perspective. The Howard Journal of Criminal Justice 27: 105-116

Nee C, White M, Woolford K, Pascu T, Barker L and Wainwright L. (2015) New methods for examining expertise in burglars in natural and simulated environments: preliminary findings. Psychol Crime Law 21: 507-513

Nonacs P. (2019) Patch Exploitation. In: Choe J (ed) Encyclopedia of Animal Behavior (Second Edition). Oxford, Academic Press, 139-148

Pires M, Guimarães P, Araújo M, Giaretta A, Costa J and Dos Reis S. (2011) The nested assembly of individual-resource networks. J Anim Ecol 80: 896-903

Portney L and Watkins M. (2015) Foundations of clinical research. Applications to practice. Philadelphia (PA), F.A. Davis Company

Pulliam HR. (1974) On the theory of optimal diets. Am Nat 108: 59-74

Pyke GH. (2019) Animal Movements - An Optimal Foraging Theory Approach. In: Choe J (ed) Encyclopedia of Animal Behavior (Second Edition). Oxford, Academic Press, 149-156

Ramos-Robles M, Andresen E and Díaz-Castelazo C. (2016) Temporal changes in the structure of a plant-frugivore network are influenced by bird migration and fruit availability. PeerJ 4: e2048

Reppetto TA. (1974) Residential crime. Cambridge (Mass.) : Ballinger

Robinson W. (1950) Ecological Correlations and the Behavior of Individuals. Am Sociol Rev 15: 351357

Rollings K. (2008) Counting the costs of crime in Australia: a 2005 update. Australian Institute of Criminology Canberra, Australia

Roughgarden J. (1979) Theory of population genetics and evolutionary ecology: an introduction. New York, Macmillan

Saramäki J, Kivelä M, Onnela J-P, Kaski K and Kertesz J. (2007) Generalizations of the clustering coefficient to weighted complex networks. Phys Rev E 75: 027105

Sih A and Christensen B. (2001) Optimal diet theory: when does it work, and when and why does it fail? Anim Behav 61: 379-390

Simon HA. (1955) A behavioral model of rational choice. Q J Econ 69: 99-118

Simpson EH. (1949) Measurement of diversity. Nature 163: 688

Stephens DW, Brown JS and Ydenberg RC. (2007) Foraging: behavior and ecology. University of Chicago Press

Stephens DW and Krebs JR. (1986) Foraging theory. Princeton University Press 
Summers L and Johnson SD. (2017) Does the configuration of the street network influence where outdoor serious violence takes place? Using space syntax to test crime pattern theory. J Quant Criminol 33: 397-420

Svanbäck R and Bolnick DI. (2005) Intraspecific competition affects the strength of individual specialization: an optimal diet theory method. Evol Ecol Res 7: 993-1012

Svanbäck R and Bolnick DI. (2007) Intraspecific competition drives increased resource use diversity within a natural population. P Roy Soc B 274: 839-844

Svanbäck R, Eklöv P, Fransson R and Holmgren K. (2008) Intraspecific competition drives multiple species resource polymorphism in fish communities. Oikos 117: 114-124

Tinker MT, Guimarães PR, Novak M, Marquitti FMD, Bodkin JL, Staedler M, Bentall G and Estes JA. (2012) Structure and mechanism of diet specialisation: testing models of individual variation in resource use with sea otters. Ecol Lett 15: 475-483

Townsley M, Birks D, Bernasco W, Ruiter S, Johnson SD, White G and Baum S. (2015) Burglar Target Selection A Cross-national Comparison. J Res Crime Delinq 52: 3-31

Townsley M, Birks D, Ruiter S, Bernasco W and White G. (2016) Target Selection Models with Preference Variation Between Offenders. J Quant Criminol 32: 283-304

Townsley M and Sidebottom A. (2010) All offenders are equal, but some are more equal than others: Variation in journeys to crime between offenders. Criminology 48: 897-917

Train KE. (2009) Discrete choice methods with simulation. Cambridge ; New York : Cambridge University Press

Turner A. (2001) Depthmap: a program to perform visibility graph analysis. Proceedings of the 3rd International Symposium on Space Syntax. 31.12

Van Daele S. (2010) Mobility and distance decay at the aggregated and individual level. In: Cools M, De Ruyver B, Easton M, Pauwel L, Ponsaers P, Vande Walle G, Vander Beken T, Vander Laenen F, Vermeulen G and Vynckier G (eds) Safety, societal problems and citizens' perceptions: new empirical data, theories and analyses. Antwerp, Maklu, 41-59

van Loon J. (2014) “Just writing your name?" An analysis of the spatial behaviour of graffiti writers in Amsterdam. Belgeo 2014

Vandeviver C and Bernasco W. (2019) "Location, Location, Location": Effects of Neighborhood and House Attributes on Burglars' Target Selection. J Quant Criminol: 1-43

Vandeviver C, Neutens T, Van Daele S, Geurts D and Vander Beken T. (2015a) A discrete spatial choice model of burglary target selection at the house-level. Appl Geogr 64: 24-34

Vandeviver C, Van Daele S and Vander Beken T. (2015b) What makes long crime trips worth undertaking? Balancing costs and benefits in burglars' journey to crime. Brit J Criminol 55: 399-420

Vanhoenacker B and Bosschaert P. (2011) Op maat van de straat. Naar een integrale kijk op graffiti en street art. Gent, Graffiti Jeugddienst vzw

Waite T and Field K. (2007) Foraging with Others: Games Social Foragers Play. In: Stephens DW, Brown JS and Ydenberg RC (eds) Foraging: Behavior and Ecology. London, The University of Chicago Press, 331-364

Walker BB and Schuurman N. (2015) The pen or the sword: a situated spatial analysis of graffiti and violent injury in Vancouver, British Columbia. Prof Geogr 67: 608-619

West L. (1988) Prey selection by the tropical snail Thais melones: a study of interindividual variation. Ecology 69: 1839-1854

Wilson DS. (1998) Adaptive individual differences within single populations. Philos T R Soc B 353: 199-205

Wilson JQ and Kelling GL. (1982) Broken windows. Atlantic Mon 249: 29-38

Wright R and Decker SH. (1996) Burglars on the job: Streetlife and residential break-ins. UPNE

Wright R and Decker SH. (1997) Armed robbers in action: Stickups and street culture. UPNE 


\section{TABLES}

Table 1. Frequencies of observed target types. Proportions don't add up to one due to rounding

\begin{tabular}{ll}
\hline Target type & N (proportions) \\
\hline Buildings & $1,135(0.596)$ \\
Electrical transformer boxes & $403(0.212)$ \\
Bridges/overpasses & $129(0.068)$ \\
Enclosures & $76(0.040)$ \\
Street furniture (benches, etc.) & $37(0.019)$ \\
Signs & $31(0.016)$ \\
Cays & $23(0.012)$ \\
Poles & $19(0.010)$ \\
Stairs & $18(0.009)$ \\
Building externalities (drainpipes, etc.) & $17(0.009)$ \\
Other & $16(0.008)$ \\
Total & $\mathbf{1 , 9 0 4 ( 1 )}$ \\
${ }^{a}$ Proportions don't add up to one due to rounding. \\
\hline
\end{tabular}


Table 2. Summary statistics for the measures of between-individual variation, nestedness and modularity

\begin{tabular}{lccll}
\hline & Metric & Value & Null95\% & P-value \\
\hline Between-individual variation & $W I C / T N W$ & 0.596 & $0.674-0.764$ & 0.001 \\
& $E$ & 0.500 & $0.406-0.466$ & 0.001 \\
Nestedness & $N O D F$ & 45.49 & $51.16-57.78$ & 0.001 \\
\multirow{3}{*}{ Modularity } & $W N O D F$ & 30.29 & $32.63-37.19$ & 0.001 \\
& $C_{W S}$ & 0.044 & $-0.003-0.011$ & 0.001 \\
& $M$ & 0.179 & $0.095-0.121$ & 0.001 \\
\hline
\end{tabular}




\section{FIGURES}

Fig. 1
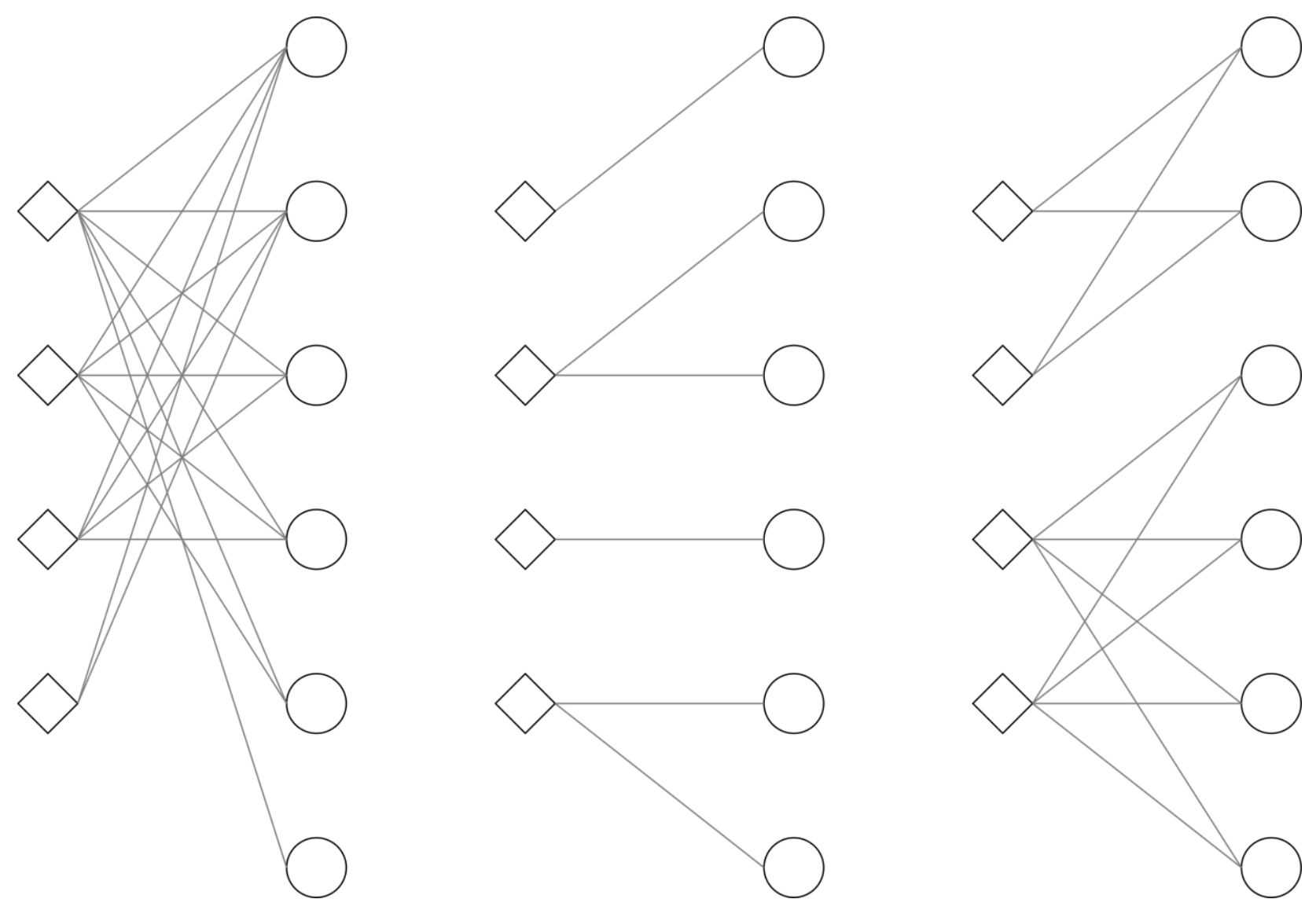

Individuals and target types are represented as diamonds and circles, respectively. Observed interactions between individuals and targets are represented by lines. From left to right: (a) Target choices of more selective offenders are nested in those who are more versatile. (b) All offenders specialize on different target types, with no overlap between choices. (c) The population of offenders consists of groups who prefer the same subset of possible targets. Choices don't overlap between groups. 
Fig. 2

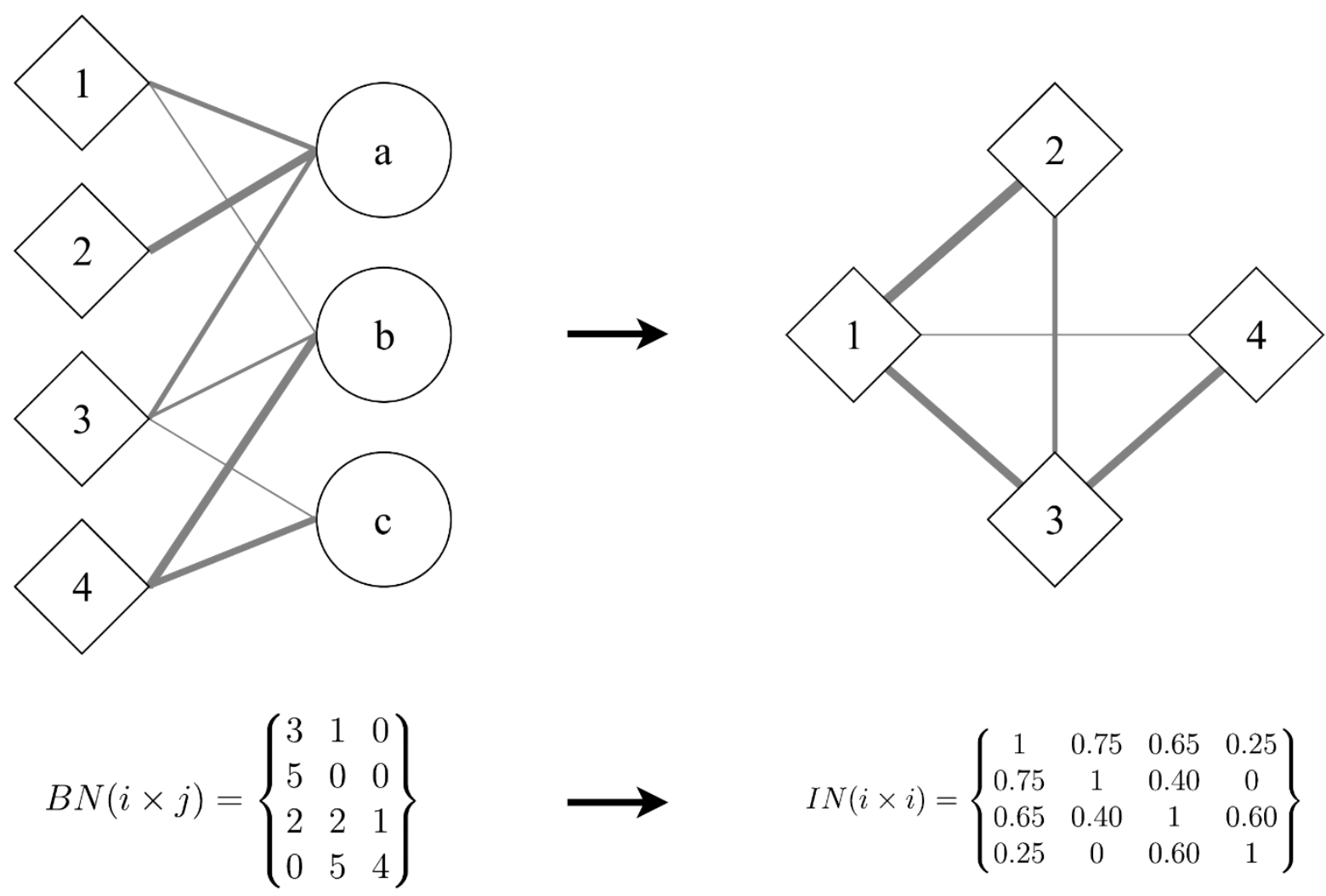

From left to right: (a) A graphical representation of a bipartite network and its matrix representation, containing four individuals and three different target types. Individuals and target types are represented as diamonds and circles, respectively. Observed interactions between individuals and targets are represented by lines, weighed by the number of observed interactions. (b) A graphical representation of the same network transformed into an individual overlap network. Individuals are represented as diamonds, with lines between them indicating the degree of overlap between individual target choices. Weighted overlap values are presented in the matrix below. 
Fig. 3

(a)

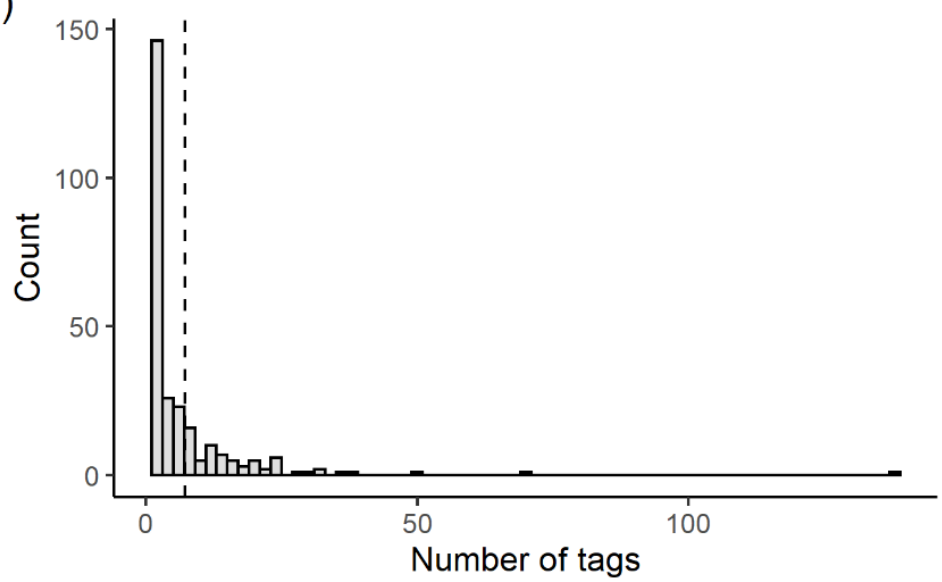

(c)

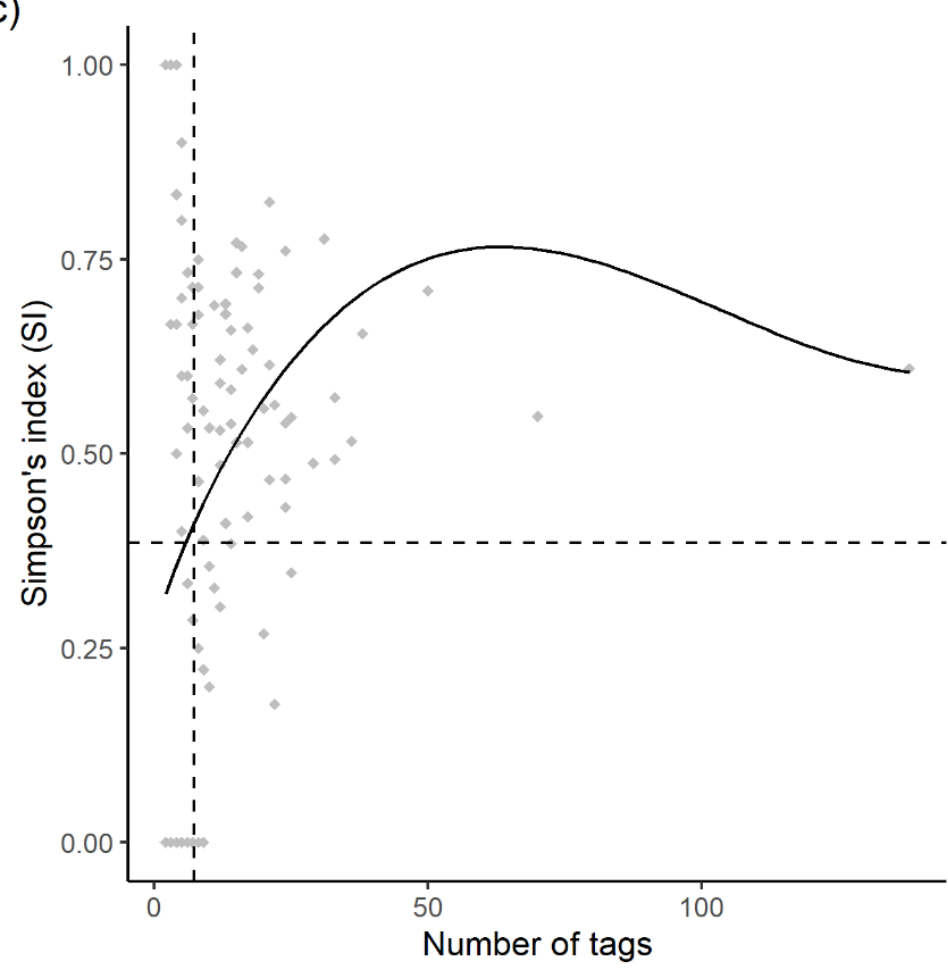

(b)

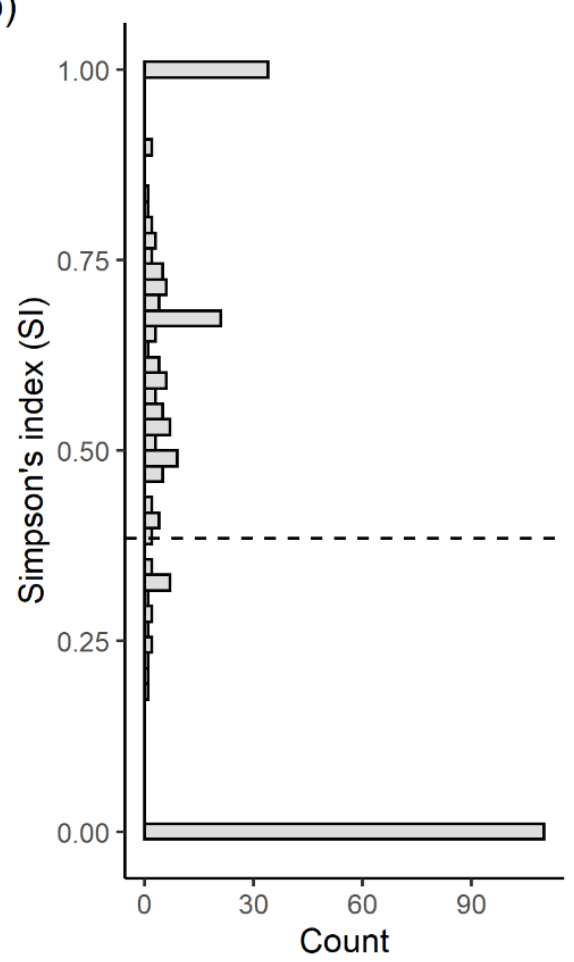

Top left (a): A frequency histogram of the number of observed tags per individual. The dashed line represents the mean. Bottom right (b): A frequency histogram of Simpson's index value per individual. The dashed line represents the mean. Bottom left (c): A scatter plot of the number of observed tags per individual versus Simpson's index. Dashed lines represent the means for each variable. The solid line represents the polynomial regression line between both variables. 